\title{
$40 \mathrm{~S} 3$ 次元足部関節挙動計測によるシューズの安定性評価
}

\author{
The evaluation of shoe stability based on the measurement \\ of three-dimensional foot joints movements
}

\author{
○田中 孝敏 (東工大) \\ 正 持丸 正明 (産総研, CREST)
}

\author{
正 宇治橋 貞幸 (東工大) \\ 河内 まき子 (産総研, CREST)
}

\begin{abstract}
Takatoshi TANAKA, Tokyo Institute of Technology,2-12-1, Ohokayama,Meguro-ku,Tokyo
Sadayuki UJIHASHI, Tokyo Institute of Technology

Masaaki MOCHIMARU,Digital Human Research Center,National Institute of Advanced Industrial Science and Technology(AIST)

CREST,JST(Japan Science and Technology Corporation)

Makiko KOUCHI, Digital Human Research Center,National Institute of Advanced Industrial Science and Technology(AIST)

CREST,JST(Japan Science and Technology Corporation)
\end{abstract}

In order to develop a kinematic/kinetic model of shoe stability, the relationship between the physical property of shoe sole material and the rearfoot movement must be known. To clarify this relationship, the 3D motion of the shank and the rearfoot was measured for the self controlled speed running on the hard and soft surface which imitated the shoes sole. Subjects were 4 volunteers. The 3D joint angles in the Joint Coordinate System were calculated and the differences between the 2 surface conditions were examined. The maximum eversion angle on the soft surface mat was significantly larger than that on the hard surface in all subjects. Two subjects were landing at the rearfoot, others were landing at mid or forefoot. It was found that the maximum abduction angle on the soft surface was significantly larger than the hard surface for mid/fore foot runners. It was speculated that the differences in rearfoot movements were caused by the loading to the calcaneus. The results of plantar pressure distribution during the running supported this speculation.

Key Words: Sports Engineering, Running Shoe, Stability, Foot Joint Movement, 3D Measurement

\section{1. 緒 言}

ランニング・シューズにはフィット性, 耐久性, 屈曲性, 通気性, 軽量性, 安定性, クッション性, 摩耗性等といった 様々な性能がある。 中でも安定性は, ランナーが不快に感じ るようなぐらうきを防ぎ, 足部関節の過度な変形が原因で起. こる稘害の防止の観点から重要な性能である.しかしランナ 一がどのような条件からぐらつきを感じているのか明らかに なっておらず，シューズの安定性を客観的に評価することが 難しい状況にある. シューズの安定性に関連した研究として は，走行姿勢を後方から撮影した画像から得られるアキレス 腱角度を指標とする研究がある ${ }^{(1)}$.これは走行時の足部関節 内外反角度の変化が安定性と関連することを示すものである. ただ, 足部関節は非常に複雑な構造をしており, 後方から観 測した前額面内での内外反角度だけでは十分な解析とは言え ない，そこで本研究ではモーションキャプチャシステムによ り詳細な足部関節の 3 次元角度の変動を計測し，より多面的 な分析を行うこととした. 先行研究より, ミッドソールがか たいシューズをランナーが安定性がよいと感じることが明ら かになっている(2). そこで本研究では走行中の足部関節 3 次 元角度がサーフェスかたさの違いによってどのように変わり うるかを明らかにし，それらをもとにシューズ安定性評価に ついて検討を行った.

\section{2. 足部 3 次元運動計測}

\section{1 実験方法}

2 種類のかたさのサーフェスを用意し，その上を走るとき
の足部関節 3 次元角度を計測した. 運動計測には，時分割発 光型のマーカを体表面に取り付け，複数台のカメラでそれを 検出するモーションキャプチャシステム（Visualeyez 3000, Phoenix Technologies 社) を用いた。実験は室内の走行路（約 $10 \mathrm{~m}$ ) で行った. 走行路にはEVA 材 (Asker-C Hardness 32 厚 さ $15 \mathrm{~mm}$ ) を敷き詰め, 運動計測装置の計測エリアの床材の みを変更した。計測エリアまでの助走距離は約 $5 \mathrm{~m}$ である. やわらかいサーフェス条件は, 走行路と同一の EVA 材とし, かたいサーフェス条件は EVA 材の代わりに, 同一厚さの足圧 分布計測装置 (emed-ST, novel 社, Asker-C Hardness 74) を設 置し，その上に着床するようにした．ランニング速度および ランニングフォームについては特に指定せず, ランナーに好 きなように走らせた.

被験者は 4 名. 年齢 $21 \sim 22$ 歳, 成人男性, 被験者 2 は競技者 であった．各被験者につき，ランニング動作 6 試行と静止立 位 1 姿勢を計測した. ランニング動作時には 6 個のマーカを 発光させ， $238 \mathrm{~Hz}$ で計測した．運動中の下腿と足部の相対運 動を知るには，足部関節を構成する下腿部脛骨座標系と足部 踵骨座標系の方向余弦が計測できればよい.このためには, 下腿部と足部に，それぞれ 3 つ上のマーカを貼り付ける必 要がある. Fig.1における○印は, ランニング動作時に計測し たマーカの位置である. 一方, これらのマーカから, 各座標 系の方向余弦を精度良く計測するには，マーカの隠れが起き ず，かつ，マーカ間の距離が十分離れていてマ一カを貼り付 けた部分での皮膚変形が小さくなければならない，さらに， 関節角度を個人間で比較するには，解剖学的な対応付けも必 要となる。これらをすべて同時に満足することは難しい，そ こで，連動中のマーカには解剖学的対応関係を考慮せず，精 度と安定性のみを考慮とするととした。 

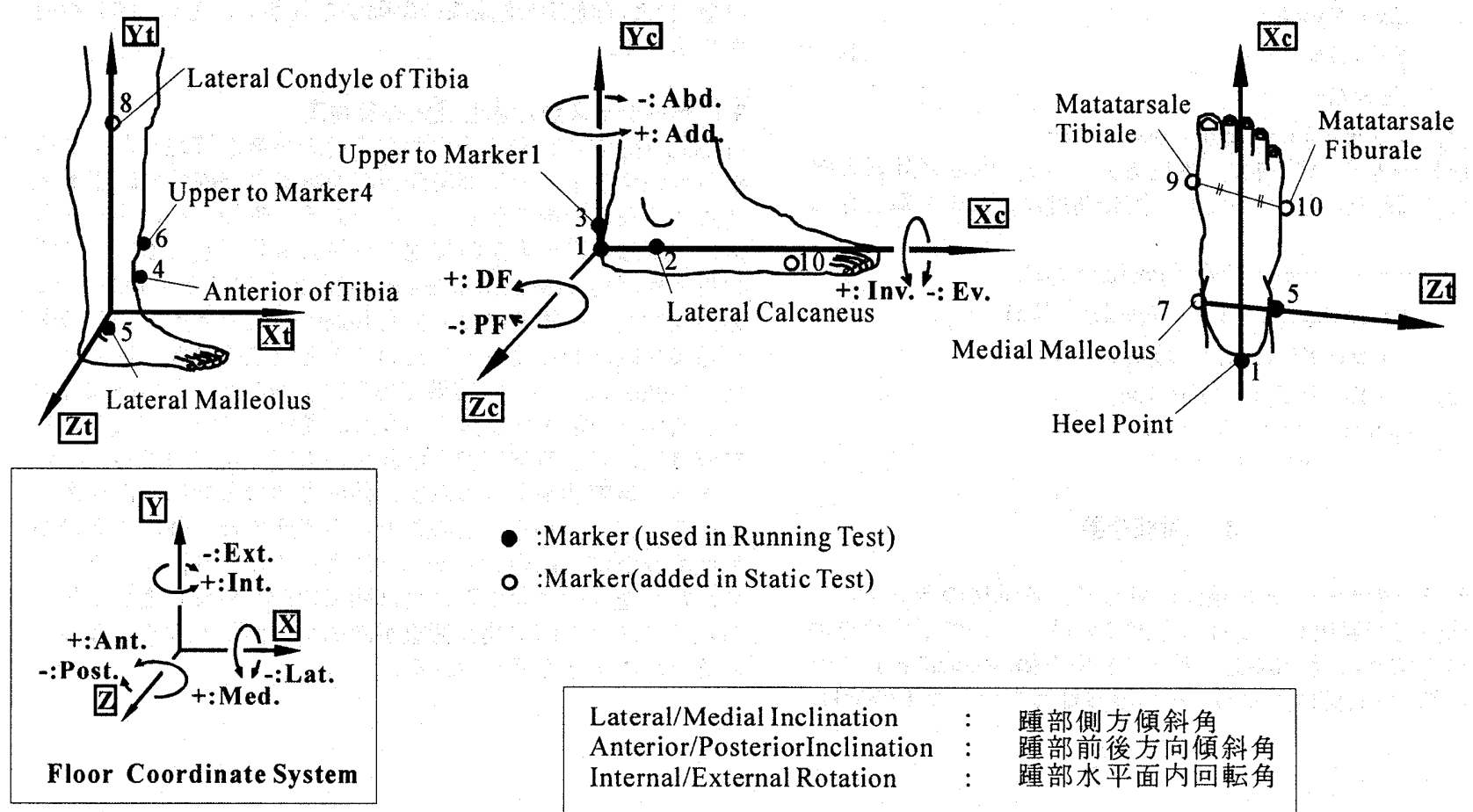

- :Marker (used in Running Test)

o : Marker(added in Static Test)

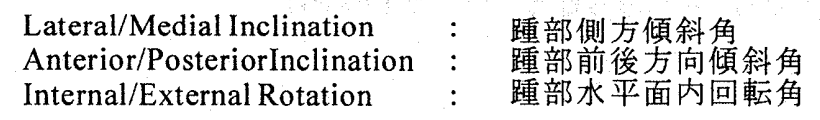

Fig.1 Definition of the calcaneus and tibia coordinate system (right foot)

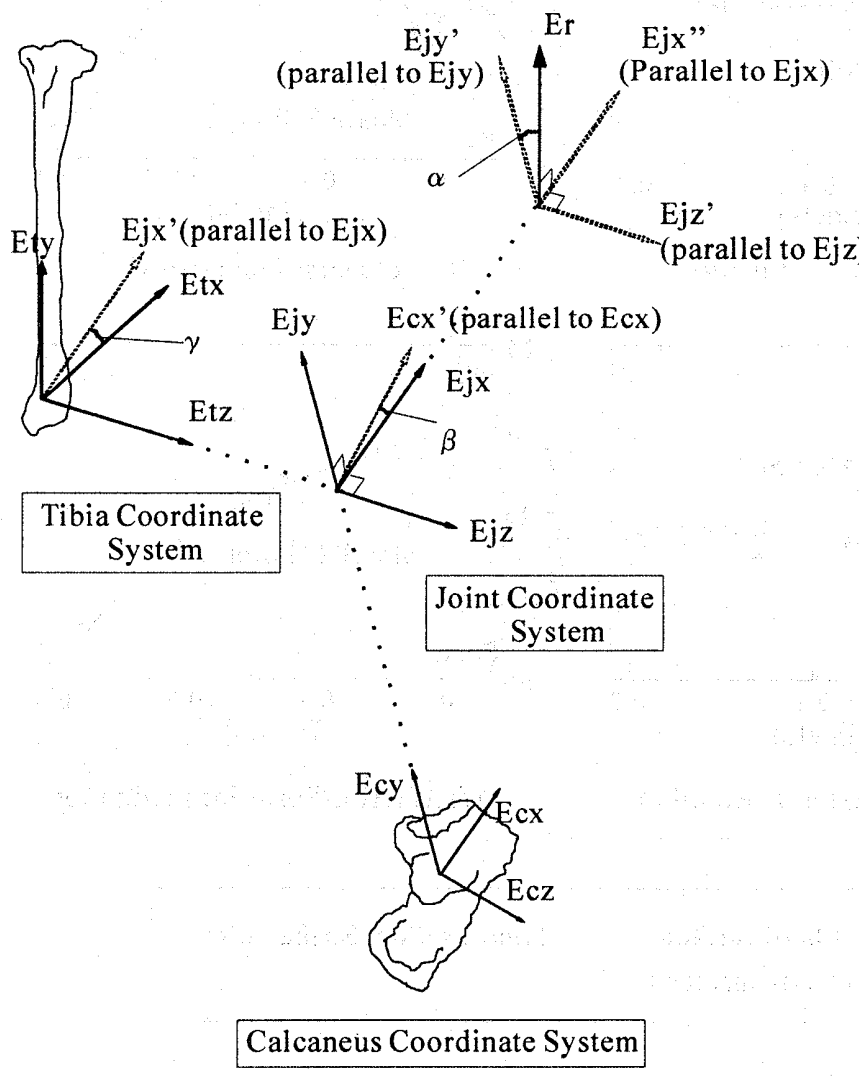

そして, 運動中のマーカと解剖学的特徵点との相対的位置関 係を知るために, さらに解剖学的特徴点の位置に 4 個のマー 力を加えた. 計 10 個のマーカの 3 次元位置を, 静止立位姿勢 で計測した. Fig.1 における○印は静止立位状態の計測で加え た 4 つのマーカの位置である.

\section{2 足部関節 3 次元座標系定義}

足部関節 3 次元角度を算出するための脛骨座標系, 踵骨座 標系を下記のように定義した。

脛骨座標系 : Zt 軸一内果・外果を結んだ直線の方向

$\mathrm{Xt}$ 軸 $-\mathrm{Zt}$ 軸と内果・外果中点と脛骨外側顆を結 んだ直線の外積方向

$\mathrm{Yt}$ 軸 $-\mathrm{Zt}$ 軸, $\mathrm{Xt}$ 軸の外積方向

踵骨座標系 : Xc 軸一脛側中足骨頭・腓側中足骨頭の中点と踵 点を結んだ直線の方向

Zc 軸一絶対座標鉛直方向上向きとXc 軸の外積 方向

$\mathrm{Yc}$ 軸一 Xc 軸と $Z \mathrm{c}$ 軸の外積方向

\section{3 足部関節角度算出方法}

静止立位時のマーカの配置と脛骨座標系および踵骨座標系 を Fig.1 に示す.足部関節は距腿・距骨下関節を一体と見なし， 脛骨座標系と踵骨座標系の相対的な内反／外反(Inversion /Eversion), 内転／外転(Adduction/Abduction), 底屈／背屈 (Plantar Flexion/Dorsi Flexion)方向の回転角度を算出した. 関節

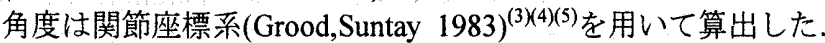
Fig.2 にその概念図を示す. 脛骨座標系の単位方向べクトルを Etx,Ety,Etz，踵骨座標系の単位方向ベクトルを Ecx，Ecy，Ecz とすると, 関節座標系(Joint Coordinate System)の単位方向べク

Fig.2 The definition of the Joint Coordinate System in foot joint トル Ejx, Ejy，Ejzは次の通りである. 


$$
\begin{aligned}
& E j x=E j y \times E j z \\
& E j y=E c y \\
& E j z=E t z
\end{aligned}
$$

ここで, X:Symbol for vector cross product.

関節座標系を用いた内反 /外反方向 $(\alpha)$, 内転 / 外転方向

$(\beta)$, 底屈/背屈方向 $(\gamma)$ の回転角度は, 次式で算出され

る.

$$
\begin{aligned}
& \alpha=\operatorname{arcos}(E r \cdot E j y) \cdot \operatorname{sign}(E j y \cdot E j z) \\
& \beta=\operatorname{arcos}(E j x \cdot E c x) \cdot \operatorname{sign}(E j x \cdot E c z) \\
& \gamma=\operatorname{arcos}(E t x \cdot E j x) \cdot \operatorname{sign}(E t y \cdot E j x)
\end{aligned}
$$

ここで, Er : Ejx と Ejz の外積方向

$\operatorname{sign}(\mathrm{x}): \mathrm{x}<0$ のとき-1

$$
\mathrm{x}>0 \text { のとき } 1
$$

\section{3. 実験結果}

それぞれのサーフェス条件に対して，各試技の全フレーム の平均角度を算出し, それら全試技の值について平均値を求 めこの平均值に近い試技のデータを中央值(Median)として作 図した ${ }^{(6)}$. 中央値は，おおよその踵接地点をマーカ 1 の絶対
座標 および関節角度曲線の挙動から判断し, その 0.04 秒前 から示した。

\section{1 サーフェスかたさと最大外反角度}

Fig.3 は被験者 1 の走行中におおよその足部が接地したところ から離地するまでの足部関節角度曲線および踵骨の床座標系 に対する角度曲線を示したものである．やわらかいサーフェ スに着床した際の方が踵接地から最大背屈が起こるまでの間 の最大外反角度(Maximum Eversion)が大きいことがわかる.こ の傾向は他の被験者についても共通の傾向であった。この観 察結果を統計的に検証するために 1 元配置の分散分析を行っ た. Tablel はその検定結果である.この結果, どの被験者で も 2 条件下で最大外反角度が有意に異なっていた. Fig.3より 床座標系に対する踵部側方傾斜角の着床直後における振幅の 大きさは足部関節角度の内反/外反方向の振幅にほぼ一致し ていることがわかる. このことから着床直後の外反方向の回 転は踵骨が側方に傾斜することによっておこり，サーフェス のかたさを変化させた際に足部関節の最大外反角度が変化す る現象は踵骨下面に働く荷重が内側が外側より大きくなって いるためであると考えられる。

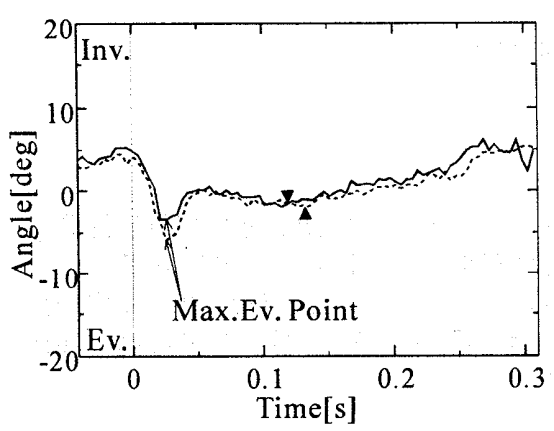

(a) Inversion/Eversion

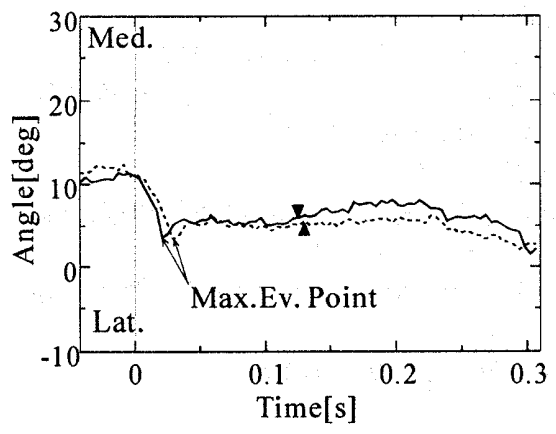

(d) Lateral/Medial Inclination

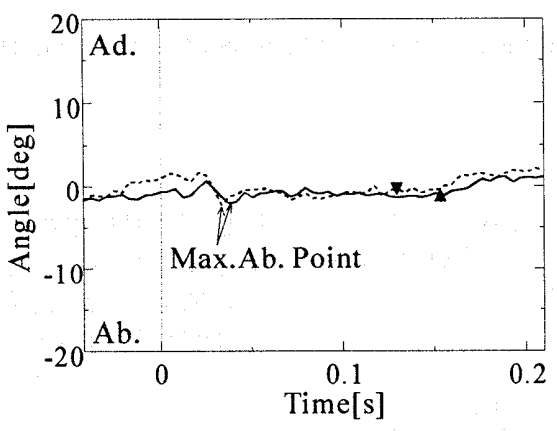

(b) Adduction/Abduction

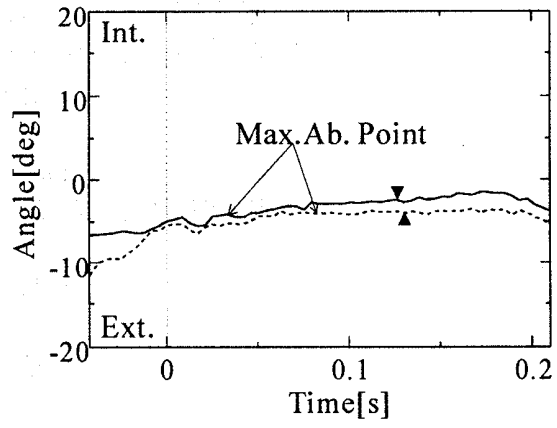

(e) Internal/External Rotation

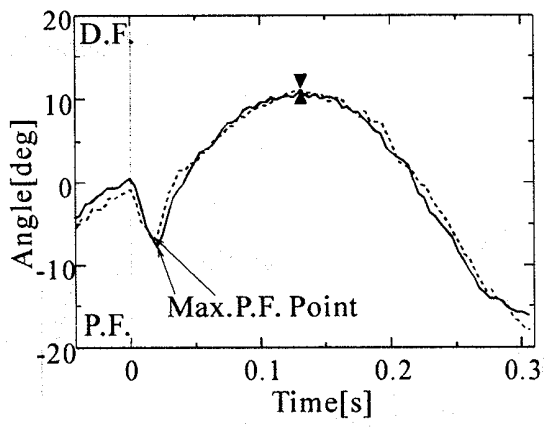

(c) Dorsi/Plantarflexion

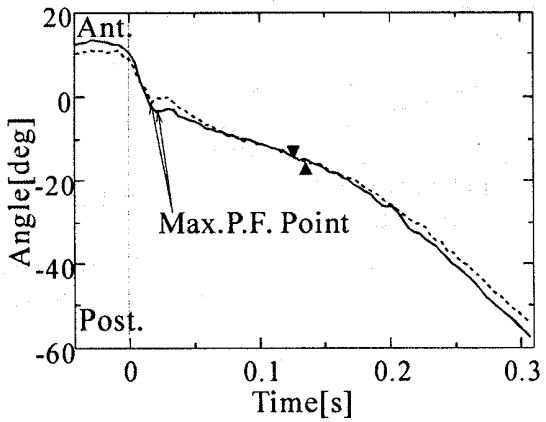

(f) Anterior/Posterior Inclination 


\section{2 サーフェスかたさと最大外転角度}

被験者 2 および 4 につてやわらかいサーフェスに着床し た場合の方が最大外転角度(Maximum Abduction)が大きくな っていることが観察された. Table 1に示すように，この傾向 は統計学的にも検証された. Fig. 4(a)のように, 被験者 4 は着 床直後に大きく外転している。しかし，Fig.4(b)より床座標に 対する着床直後における踵部水平面内回転の振幅は明らかに 小さい．同様の傾向は被験者 2 にもみられた.

このことから両被験者の着床後の外転は脛骨が水平面内内側 に回転することにより生していることが分かる. またやわら かいサーフェスに着床した場合の方が脛骨が大きく回転して いることから，より大きい回転トルクが脛骨に働いているも のと考えられる.

Table 1 Results of analysis of variance

\begin{tabular}{l|cccc}
\hline Rotative Direction & \multicolumn{4}{|c}{ Result of F-test } \\
\hline Maximum Eversion & $* *$ & $* *$ & $*$ & $* *$ \\
Maximum Abduction & $\mathrm{ns}$ & $* *$ & $\mathrm{~ns}$ & $*$ \\
Maximum Plantarflexion & $\mathrm{ns}$ & $\mathrm{ns}$ & $\mathrm{ns}$ & $*$ \\
\hline
\end{tabular}

subject 1 subject 2 subject 3 subject 4

\section{3 走行中の踵骨挙動に関する力学的考察}

Fig. 3 (a), (c)より, 被験者 1 は着床直後に大きく底屈方向, 外反方向に回転している，踵骨の床座標系に対する角度曲線 からも着床直後に後方向，外側方向に傾斜し，その後，前方 向，内側方向に回転していることがわかる. 被験者 3 にも同 様の傾向が見られた。

このことから，着床時に大きな荷重が踵部に働いており， 長足底鞋帯, 三角勒帯脛踵部といった部分に大きな引っ張り 荷重が働いているものと考えられる.

Fig. 6 に被験者 1 , および 2 の着床時の圧力分布中心の軌跡 を示す。この図から被験者 1 が踵部分から着床し，大きな荷 重が鍾部に働いていることが分かる。すなわち，被験者 1 お よび 3 は踵から着床する走法(Rearfoot Running)をしていると 考えられる.

Fig. 5 のように被験者 4 は被験者 1,3 のような着床直後の 踵部側方傾斜，踵部前後方向傾斜は見られない。この被験者 は着床時に踵部に働く衝撃荷重は非常に小さく, その代わり に他の被験者に比べて大きな衝撃荷重が中足部に㗢いている ものと考えられる.このことから被験者 4 は前足部から着床 する走法(Forefoot Running) をしていると考えられる.

${ }^{* *}: \mathrm{p}<0.01, *: \mathrm{p}<0.05$

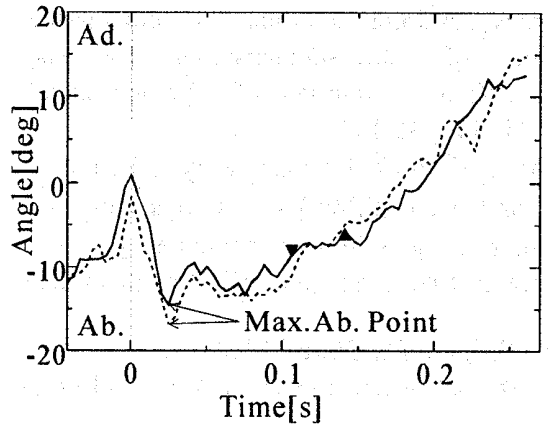

(a) Adduction/Abduction

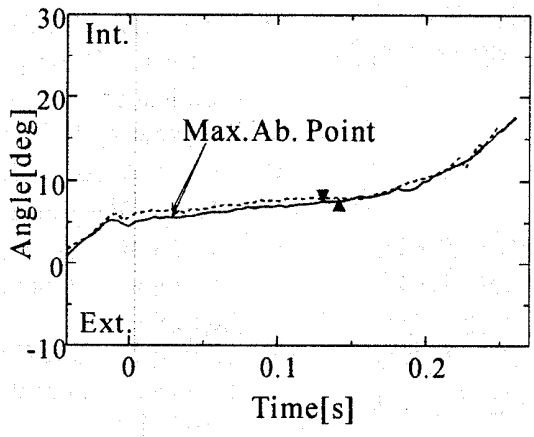

(b) Internal/External Rotation

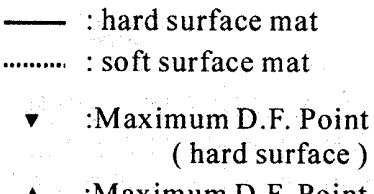

- :Maximum D.F. Point ( soft surface)

Time $0 \mathrm{~s}$ :Foot Strike Point

Fig.4 Median trial(Ad./Ab.,Int./Ext.) for subject 4

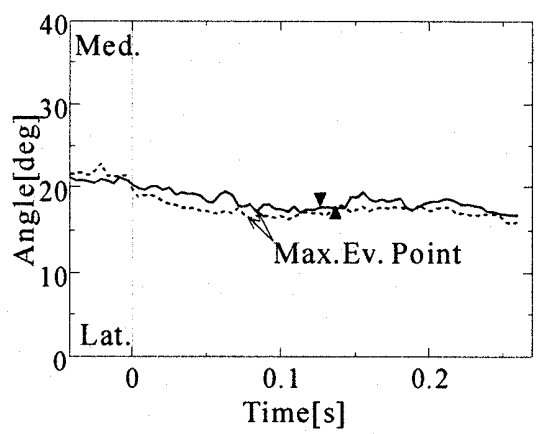

(a) Lateral/Medial Inclination

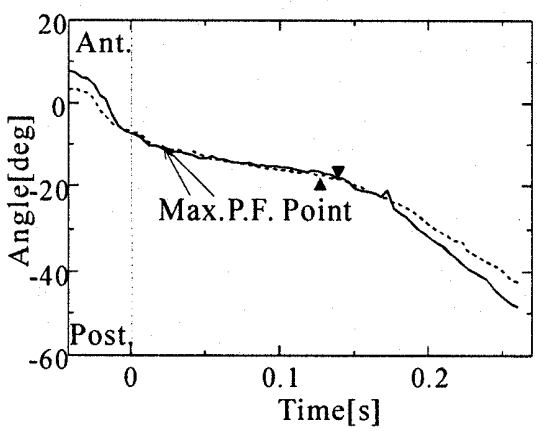

(b) Anterior/Posterior Inclination
- : hard surface mat

.......... : soft surface mat

- :Maximum D.F. Point ( hard surface)

- :Maximum D.F. Point ( soft surface)

Time $0 \mathrm{~s}$ :Foot Strike Point

Fig.5 Median trial (Lat./Med.,Ant/Post) for subject 4 
被験者 2 は着床直後に大きく外反し, 踵骨も外側方向に傾斜 している。しかし底屈方向への回転, 踵部前後方向傾斜は見 られなかった。内転/外転方向の振幅梳被験者 1 および 3 よ り大きなものとなった.このことから，被験者 2 は着床時に 踵部, 中足部の両方に衝撃荷重が分散して㗢いているものと 考えられる. Fig. 6 から被験者 2 の圧力分布中心の軌跡が中足 部外側からはじまり，軌道が踵骨下部と母子球下部の閒を通 つていることからも荷重が中足部, 踵部に分散していること が分かる。すなわち, 被験者 2 は足全体で着床する走法 (Midfoot Running)をしていると考えられる.

\section{4 足部関節角度と衝撃吸収}

以上の結果から足部関節角度はやわらかいサーフェスに着 床した方が大きくなる傾向がみられた。

しかし，足部に伝わる衝撃エネルギはかたいサーフェスに 着床した場合の方が大きい. 一般に着床時の衝撃は筋収縮に よる力と逆方向に筋肉が伸び, 負のエネルギを発生させるこ とにより吸収されていると言われている．すると足部に働く 衝撃エネルギが大きいかたいサーフェスに着床した際の方が 関節角度の振幅は大きいはずである。しかし結果からはその ような傾向は見られなかった。

この結果から足部関節周りの勒帯が着床時の衝撃エネルギ を吸収する能力は，膝関節周りの筋肉などに比べて小さいの ではないかと考えられる。つまり，足部関節は衝撃吸収の機 能をあまり含んでおらず，足部のぐらつきは，傷害の要因に なると考えられる。このぐらつきや傷害を防ぐことがランニ ング・シューズに求められる安定性である。このことから， 足部関節角度はランニング・シューズの安定性を判断する指 標として有効であると考えられる。

\section{4. 結論}

本研究では，足部に関節座標系を定義し，解剖学的意味を 持つ足の姿勢を表す 3 次元角度を定義し，この定義に基づき ランニング動作時における足部関節の姿勢を計測した。その 結果, 着床するサーフェスのかたさを変化させると, 足部関 節の 3 次元角度が変化することが分かった.この足部の 3 次 元角度の変動は踵部のぐらつきを表しており, シューズある いはサーフェスの安定性評価指標として有効であることが示 唆された.このことから, どのようなメカニズムで足部関節 3 次元角度の変動が起こるのかを明らかにすることができ， 足部の傷害メカニズムの解明にもつながることが期待できる.

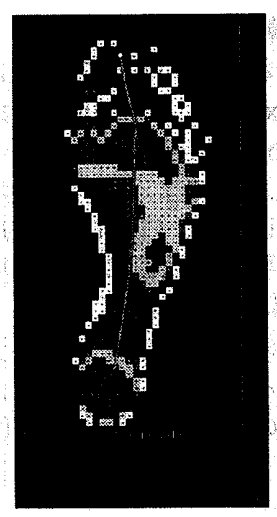

Subject 1

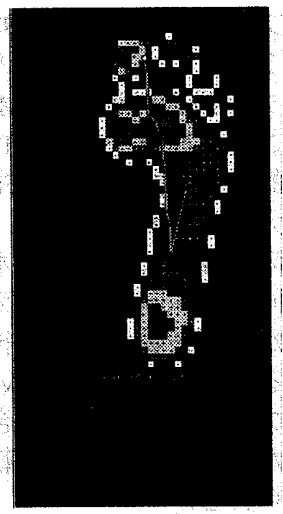

Subject 2
Fig.6 The Truck of Center of Pressure

\section{文献}

(1) Benno M.Nigg, M.Morlock, The influence of lateral heel flare of running shoes on pronation and impact force, Medicine and Science in Sports and Exercise Vol.19 No.3 (1987) 294-302.

(2) Katsumasa Tanaka,Hayata Uwai,Sadayuki Ujihashi,A method of measurement and evaluation of the mechanical properties on the stability of running shoes, $6^{\text {th }}$ Symposium on Footwear Biomechanics(2003),93-94.

(3) E.S.Grood, W.J.Suntay, A Joint Coordinate System for the Clinical Description of Three-Dimensional Motions: Application to the Knee, Journal of Biomechanical Engineering Vol.105 (1983) 136-144.

(4) Robert W.Soutas-Little, Glenn C.Beavis, Mary C.Beavis, Mary C.Verstraete, and Trena L.Markus, Analysis of foot motion during running using a joint co-ordinate system, Medicine and Science in Sports and Exercise Vol.19 (1987) 285-293.

(5) Nigg,B.M.,Cole,G.K.,Wright,I.C., Optical Methods, Biomechanics of the Musculo-skeletal System, WILEY (1999), 302-331.

(6) M.C.Carson, M.E.Harrington, N.Thompson, J.J.O'Connor, T.N.Theologis, Kinematic analysis of a multi-segment foot model for research and clinical applications:a repeatability analysis, Journal of Biomechanics Vol.34 (2001) 1299-1307. 